Article

\title{
Real-Time Data Utilization Barriers to Improving Production Performance: An In-depth Case Study Linking Lean Management and Industry 4.0 from a Learning Organization Perspective
}

\author{
Henrik Saabye ${ }^{1, *(\mathbb{D}}$, Thomas Borup Kristensen ${ }^{2} \mathbb{C}$ and Brian Vejrum Wæhrens ${ }^{1}$ \\ 1 Department of Materials and Production, Aalborg University, 9000 Aalborg, Denmark; bvw@mp.aau.dk \\ 2 Aalborg University Business School, Aalborg University, 9000 Aalborg, Denmark; borup@business.aau.dk \\ * Correspondence: henrik.saabye@velux.com; Tel.: +45-5215-9273
}

Received: 11 September 2020; Accepted: 19 October 2020; Published: 22 October 2020

\begin{abstract}
This study presents empirical evidence for the ongoing discussion about the link between Lean Management (LM) and industry 4.0 (I4.0) by exploring a non-technical perspective on how manufacturers can capitalize on their technological investments. The paper, therefore, studies the link between LM and I4.0 from a learning organization (LO) perspective by examining the implementation, commissioning, and utilization of a real-time operational data gathering system at a Danish building material manufacturer. This six months in-depth case study finds that for the manufacturer to utilize real-time operational data from a LO perspective, several barriers must be addressed: problem solving that is not initiated by operators, operators who do not have second-order problem-solving abilities, operators who perceive the new real-time data technology as coercive, poor learning environments and processes, and a lack of leadership that supports learning. This study can help practitioners understand the importance of balance, the prevalent technocentric focus when implementing new I4.0 technologies with a LO focus. Furthermore, the study provides practitioners with a list of specific barriers from a LO perspective to be mindful of when aiming to combine LM and I4.0 to improve production performance.
\end{abstract}

Keywords: lean management; Industry 4.0; learning organization; enabling formalization; real-time data; OEE

\section{Introduction}

I4.0 is presented as a promising set of integrated digital technologies to improve production performance significantly and bring manufacturing into the digital age [1]. A core capability of these I4.0 technologies, when combined, is to institute a level of intelligence to production lines by monitoring and eventually controlling physical machines [1-3]. By adopting I4.0 technologies, the manufactures can develop their production setup to potentially become both more effective and flexible in producing highly customized products on a large scale while still staying competitive regarding high productivity and continuously lowering costs per produced unit [4].

Therefore, manufacturers have invested many resources into acquiring these new I4.0 technologies to develop their productions system to be more flexible and productive [5]. However, when investing heavily in I4.0 technologies, the capital investment gets tied to the production machinery, and the depreciation cost of these investments is often quite irreversible and possesses low variability. Therefore, such investment poses financial risk if the technology is not successfully utilized [6]. To ensure full capitalization of manufactures' I4.0 technology investments, the literature suggests implementation in conjunction with process excellence methodologies like Lean Management (LM) [7-9]. 
However, most extant literature exploring how I4.0 and LM can elevate production performance focuses on how to enhance the technical tools and methods of LM [7]. Only focusing on the technical side of linking I4.0 and LM imposes a significant risk that the implementation of I4.0 technologies will become stranded in a fledgling state. Many I4.0 implementations will, as such, not be able to fulfill the very ambitious and novel performance standards reported in discussions of I4.0, just as it has happened with many LM efforts [10-12]. This amounts to a call for a strengthened focus on the non-technical aspects like learning organization (LO) practices and behaviors when manufacturers adopt I4.0 technologies in conjunction with LM for improving production performance $[7,13,14]$. Conceptually, LM can, from the extant literature, be understood from both a technical perspective and a non-technical perspective. The technical LM perspective is related to technologies and tools like pull-systems, Kanban, and value stream mapping [7]. The non-technical perspective is related to human and cognitive elements like learning, collaboration, and leadership [15]. Analogously, we can understand I4.0 from both a technical and non-technical perspective. For I4.0, the technological perspective is the most prevalent in the extant literature and is related to technologies like real-time data, Internet-of-things, and autonomous robots $[1,13]$. However, non-technological perspectives of I4.0 are also on the rise and are related to learning, people development, and managerial aspects [13]. They are also similar to the non-technological aspects of LM. From an explanatory point of view, this study perceives LO practices and behaviors as underlying and overlapping factors in linking and mediating I4.0 and LM, as illustrated in Figure 1.

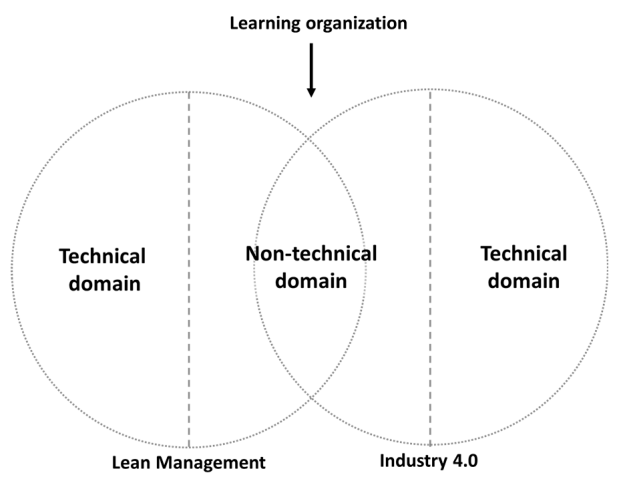

Figure 1. Conceptual association between Lean Management (LM) and I4.0 from a learning organization (LO) perspective.

The research area exploring the intersection between I4.0 and LM from an LO perspective is scarce beyond the existing explanatory literature [7]. Tortorella et al. [13] have, for example, empirically investigated the association between LO and the adoption of I4.0, and Tortorella and Fogliatto [15] have done the same between LO and LM, but only quantitively. The aim of this paper is, therefore, first to follow-up on Buer et al.'s [7] call for additional empirical research on how to link I4.0 and LM. Subsequently, it is to follow-up on recent survey-based research to examine more profoundly and to validate the positive effects that come from focusing on $\mathrm{LO}$ when adopting I4.0 in conjunction with LM $[13,15]$.

A logical first step for many manufacturers, when embarking on a transformation towards the digitalization of their production system, is to acquire I4.0 technologies that provide real-time data to help monitor and improve the performance of machines and production lines [16]. This paper examines, as an in-depth field study, the implementation, commissioning, and utilization of a real-time operational data capturing system, based on OEE (Overall Equipment Effectiveness) data, at a LM-intensive Danish manufacture. In the wake of implementing the real-time operational data capturing system, the manufacturer had, after six months, experienced no significant increase in production performance. The first author observed that the manufacturer had not advanced their existing LM work routines 
after implementation. They continued to practice reactive management-initiated problem solving of production issues, weekly, based on historical operational data.

The scientific issue behind this real-life problem is the underlying non-technocentric variables of why the manufacture was not able to enable its organization to both explore and exploit real-time operational data systems. A central element with this scientific issue is related to real-time data in a manufacturing context. The commission of real-time data comes with new opportunities but also challenges for manufactures. Real-time data has the potential to both significantly reduce the time spent identifying and correcting operational issues like unplanned machine stops and, through predictive maintenance, prevent operational issues happening in the first place [1]. The significant challenges are non-technical and associated with the multifaceted change process of shifting leaders and employees from working reactively to proactively. In a manufacturing context, this challenge is related to adding new learning routines and work practices on the shop floor. This study, therefore, proposes the following research question: What are the barriers for operators to utilize real-time operational data in improving production performance in conjunction with lean management, from a learning organization perspective?

To answer the research question, the paper will first review the relevant literature linking I4.0 and LM with concepts and practices related to LO. The methods section uses an applied case study research approach, based on a variety of in-depth qualitative data, like interviews, observations, and archival data gathered from different sources at the case company. Subsequently, we triangulate and analyze this data and outline a set of barriers related to LO for utilizing real-time operational data to improve production performance. We use these findings in the discussion and conclusion section to elaborate on how to link LM and I4.0 from a LO perspective, by outlining the elements that can prevent manufactures from utilizing real-time operational data in conjunction with LM to improve production performance.

\subsection{Literature Review}

\subsubsection{Linking LM and I4.0 Using a Learning Organization Perspective}

The literature explains LM implementations most unsuccessfully, with an imbalanced technical focus on applying LM tools to improve processes, over the LO aspects of LM [12,14,17-19]. In this regard, all organizations need to learn how to continuously improve processes and develop how they adopt and utilize new technology daily, to achieve the organization's strategic objectives while leaders and employees are simultaneously developed [20,21].

We, therefore, base this study on Edmondson and Moingeon's [22] (p.28) definition of LO practices as the process by which an organization's members actively use data to guide behavior in such a way as to promote the ongoing adaptation of the organization. The presence of real-time data will not necessarily lead to better performance if the organization is not able to transform the data into valuable actions or adjust existing process standards and daily work routines to utilize the new technology. Likewise, developing new digital versions of LM tools will not make a significant impact if not utilized as a part of learning processes within a LO.

We found positive associations between LM and LO among several authors in the operation management literature. These studies can be divided into studies highlighting learning systems and learning environments as associating concepts between LM and LO, e.g., [23-25]. Other authors focus more specifically on problem-solving practices as associating concepts, e.g., [26,27].

To advance this study's objective of empirically exploring how to link LM and I4.0 from an LO perspective, as opposed to the prevalent focus on technical aspects found in extant literature $[7,28]$, we consolidated a comparison between the technical domain of both LM and I4.0 and how they are linked associated through the LO domain in Table 1. 
Table 1. Comparison between LM's and I4.0's technical and LO domain.

\begin{tabular}{|c|c|c|c|c|}
\hline & LM Technical Domain & LO Domain & I4.0 Technical Domain & References \\
\hline Perspective & Technocentric (Analogue) & Sociocentric & $\begin{array}{l}\text { Technocentric } \\
\text { (Digital) }\end{array}$ & \multirow{6}{*}[7,16,19,20,29-34]{} \\
\hline Type of resource & Tangible & Intangible & Tangible & \\
\hline Primary functional concern & What to & How to & What to & \\
\hline Key concepts & $\begin{array}{l}\text { Elimination of waste, } \\
\text { continuous improvement, } \\
\text { zero defects, just in time } \\
\text { deliveries, Pull of raw } \\
\text { materials, multifunctional } \\
\text { teams, decentralization, } \\
\text { integration of functions, } \\
\text { vertical information systems }\end{array}$ & $\begin{array}{l}\text { Supportive learning } \\
\text { environment, specific } \\
\text { learning processes, } \\
\text { leadership that supports } \\
\text { learning, second-order } \\
\text { problem solving, enabling } \\
\text { formalization, teamwork, } \\
\text { respect for people }\end{array}$ & $\begin{array}{l}\text { Process integration, real-time } \\
\text { information transparency, } \\
\text { Virtual representation of the } \\
\text { real-world, Autonomy, } \\
\text { Product servitization, } \\
\text { servitization of manufacturing } \\
\text { capabilities, predictability, } \\
\text { Modularity, and } \\
\text { reconfigurability }\end{array}$ & \\
\hline Key technologies/ practices & $\begin{array}{l}\text { Andon, Heijunka, Kanban, } \\
\text { SMED, Poka Yoke, } \\
\text { Standardised work, } \\
\text { Statistical process control, } \\
\text { Takted production, Total } \\
\text { productive maintenance, } \\
\text { Value stream mapping, 5S, } \\
\text { 7 QC tools }\end{array}$ & $\begin{array}{l}\text { Ensuring Psychological } \\
\text { Safety, Appreciation of } \\
\text { Difference, Openness to } \\
\text { New Ideas, Time for } \\
\text { Reflection, Information } \\
\text { Collection, Scientific } \\
\text { problem solving (PDCA), } \\
\text { knowledge sharing, gemba } \\
\text { walks, empowerment, } \\
\text { commit to self-development, } \\
\text { coach and develop others, } \\
\text { create vision and align goals }\end{array}$ & $\begin{array}{c}\text { Big data \& analytics, } \\
\text { Simulation, autonomous robot, } \\
\text { Internet of things, } \\
\text { Cyber-physical-system, Cloud } \\
\text { computing, Virtual and } \\
\text { augmented reality, } \\
\text { Machine-to-Machine } \\
\text { communications, } \\
\text { cybersecurity }\end{array}$ & \\
\hline Deployment & $\begin{array}{c}\text { Specialist driven, } \\
\text { functional training } \\
\text { (Coercive formalisation) }\end{array}$ & $\begin{array}{c}\text { Leader facilitated and } \\
\text { employee-driven, contextual } \\
\text { learning }\end{array}$ & $\begin{array}{l}\text { Specialist driven, functional } \\
\text { training (Coercive } \\
\text { formalisation) }\end{array}$ & \\
\hline
\end{tabular}

\subsubsection{Second-Order Problem Solving}

A critical LO capability for any organization applying LM and aiming to utilize I4.0 is the organization's capability to improve performance by adopting scientific problem-solving practices $[21,33,35,36]$. Essential to scientific problem-solving practices is Plan, Do, Check, Act (PDCA), a generic learning model for defining a problem, identifying the underlying causes, developing and testing countermeasures, and instituting new standards and work routines [37,38]. In many cases, problem solving is understood only as a technical process improvement practice, without surfacing the underlying LO aspects [14,27]. The practice of instructing operators, from a technical point of view, on how to follow a set of predefined steps in problem solving and analytical tools, but neglecting the learning and cognitive aspects, has led to many failed attempts at LM and building LO able to effectively improve performance [38-40].

In both theory and practice, scientific problem-solving practices are closely related to LO practices $[26,27,31]$. They share the underlying learning and cognitive process of defining deviation from the desired state, identifying the root-causes of the current deviation, and subsequently implementing a set of potential countermeasures to close the deviation and reach the desired state [21,41]. An organization's ability to perform second-order problem solving daily is central to changing or adjusting its day-to-day work routines to respond to changes in the production processes, which eventually leads to improved performance [22,36,42].

The consequences of ignoring the $\mathrm{LO}$ side of problem-solving practices often lead to a problem-solving behavior pattern, characterized as overcoming the immediate obstacle, assuming what the problem is, short term-fixes, and ignoring the underlying root causes. Tucker et al. [36] observed this kind of problem-solving behavior pattern among hospital staff, and Worley and Doolen [42] had similar experiences from observing a lean transformation. From an LO perspective, we can define the latter form of problem-solving behavior as first-order problem solving instead of second-order problem solving $[36,43]$. Second-order problem solving is a cognitive approach that focuses on identifying underlying root-causes. Identification of root causes happens through investigating current work routines and practicing in-depth questioning to identify the underlying root-causes preventing an organization from obtaining a specific goal $[36,38,41,43]$. 
A potential of adopting I4.0 technology is that it can display operation performance data in real-time and automatically generate performance analyses [1]. Nevertheless, like any analog-generated data, automatically generated analyses based on real-time data still requires an underlying second-order problem-solving process. I4.0 technologies can help operators with automated signals and alerts when deviations occur. However, the operators still need, for example, to apply second-order problem solving to define the performance gap that needs to be closed, as well as identifying the underlying root causes and specific countermeasures to close the gap. The latter also requires a structured approach to experimentation. Real-time data, utilized in conjunction with second-order problem-solving practices, has the potential to considerably reduce the time it takes from when a problem is perceived to when it is solved [44]. Firstly, real-time data can immediately indicate when there is a deviation from the desired state. Then, the digitally captured data can assist the problem solver in both defining the magnitude of the gap and provide data for root cause analysis. Lastly, real-time data can provide instant feedback when experimenting with potential countermeasures.

\subsubsection{Enabling Formalization}

Manufacturers cannot expect operators to automatically embrace new daily work routines of engaging in second-order problem-solving efforts and utilizing the presence of real-time data to remove root-causes. According to Adler and Borys [29], it requires an enabling formalization of work routines, e.g., how to handle deviations and how to utilize real-time data. Manufacturers need to ensure that operators perceive new digital technologies as something that enables them to improve their processes in their daily work. There exist two types of formalization: coercive and enabling [29]. If the formalization of work routines is coercive, operators will perceive the purpose of new digital technologies as a way for management to ensure compliance of rules and procedures by controlling their work. The underlying logic behind the coercive formalization is that experts and leaders can design optimal work standards for operators to follow. However, the consequences of coercive formalization are that that operator separates themselves from their workplace and becomes alienated instead of becoming committed to daily improvements and problem solving [29,45].

Conversely, when the formalization of new work routines is enabling, they are designed to support operators in performing their daily tasks and assists them when deviations from regular operation occur. Enabling formalization of work routines embodies LO practices and dialogue between the operators, specialists, and management, which celebrates problems as an opportunity to learn and to improve performance together [21,46]. When formalization is enabling, there also exists a high degree of mutual trust between different layers of hierarchy, where the operators do not fear reprimands in case of mistakes.

\subsubsection{Supportive Learning Environments and Learning Processes}

A linking characteristic between enabling formalization and LO is the presence of a supportive learning environment consisting of supporting leaders, contextual training, and adequate time to reflect and experiment [20,29,31,32]. According to Garvin et al. [31], a supportive learning environment constitutes an environment where operators feel safe disagreeing with others. They can, for example, freely ask naive questions, own up to mistakes, and present minority viewpoints, along with having the time to reflect, explore new ideas, conduct experiments, and share knowledge. This understanding is supported by Marsick and Watkins [32], who also mention that, in a supportive learning environment, learning is an integrated part of the operator's daily work. When learning is an integrated part of daily work routines, it becomes natural for operators to develop and improve processes together with co-workers, including the ability to express their views and the capacity to listen to and inquire about the views of others [45].

A supportive learning environment also accompanies internal and global transparency by consisting of both high- and low-technology systems to capture and share learning across departments, while helping operators to see how their work is affecting the rest of the organization $[29,32]$. 


\subsubsection{Leadership That Supports Learning}

A supportive learning environment with formalized learning processes is strongly influenced by the behaviors of its leaders $[19,31,32]$. A supportive leader acts on a basic underlying assumption that she is not the one who adds value to the produced products. It is the operators on the shop floor who create the value. The type of leadership behavior required to enable operators to increase the value created for the manufacturer's customers is described in both the existing LO literature $[31,32]$ and the LM literature $[19,20,23,38]$.

One of the central principles for a leader when growing a LO with strong second-order problem-solving abilities is to foster a learning environment with a focus on both striving towards perfection and not blaming operators when failures occur. A leader must embrace failure as an opportunity for improvement and learning by enabling, developing, and empowering operators in second-order problem solving to identify and eradicate root-causes $[20,31,32,43]$. A fundamental practice of leaders in a LO is to develop their operators using the principle of 'going to Gemba'. 'Going to Gemba' means that the leaders go to the place where the organization creates its value, e.g., the shop floor, to understand the current situation and, through coaching and mentoring, supports and develops operators in their problem-solving efforts towards the desired state of operation $[19,20,23,43]$.

\section{Materials and Methods}

\subsection{The Case Company}

The case company is a production subsidiary of a global family-owned manufacturer of building material founded in the 1940s. Today, the parent company has more than 11,000 employees globally, with its headquarters in Denmark. The case company was the first production subsidiary out of 27 production sites located in 10 different countries under the parent company. Located in the western part of Denmark, the case company employs 450 blue and white collared members of staff. The case company is furthermore characterized as an LM-intensive manufacturer and has successfully applied LM in combination with automation for over two decades.

For the case company to cope with expected growth scenarios without just investing in additional production lines, a digital transformation is one of its top strategic priorities. The first step of the case company's digitalization strategy regarding production is to implement new I4.0 technologies that can support a transformation from reactive machine maintenance, reactive repair, and problem-solving practices to preventive maintenance and a proactive repair and problem-solving approach. The case company expects that implementing new I4.0 technologies will allow operators and leaders to monitor the overall status of the operation through real-time indicators of operating conditions and production indicators that can enable preventive maintenance, proactive repair, and problem solving. After successful technology implementation, the case company expects to have algorithms using historical data to detect indicators of potential unplanned stops and deviations from normal operation. The intention is to incorporate them into effective problem solving and decision-making to improve production performance in real-time [1].

The first technology implemented in this digital transformation process is a real-time operational data gathering system, in one of the case company's departments. This technology implementation is the primary research object in this case study.

\subsection{Research Approach}

Understanding the barriers to implementing and utilizing a real-time operational data gathering system from an in-depth, non-technical perspective at the case company calls for a qualitative and explorative research method to collect and analyze data. A qualitative and explorative research method aided the research aims of clarifying the exact nature of the problem associated with barriers to utilizing real-time operational data in a manufacturing context. Since our research through theory refinement/elaboration aimed to contribute to the body of knowledge by developing an in-depth 
understanding of the social phenomenon of advancing LM in conjunction with I4.0 technology, we applied a case study method [47-49].

A case study approach is a recognized research method for observing and describing a complex social phenomenon within the field of operations management. A case study is also useful for conducting empirical research and theory refinement/elaboration when performing a study within the organizational context where the phenomenon occurs $[47,48]$. Especially when studying LM, several academics have based their research strategy on a case study approach, e.g., [11,42,50].

\subsection{Data Sources}

\subsubsection{Sampling}

To study the phenomenon of adopting a new real-time operational data gathering system at the case company and thereby increase our understanding of barriers to utilization, we wanted to explore the different perceptions among the identified informants in Table 1. Firstly, we selected key, knowledgeable informants based on their involvement in both the implementation and the following utilization of the real-time operational data gathering system. We have outlined the different identified informants and their organizational roles in Table 2.

Table 2. Case study sources (first sampling).

\begin{tabular}{|c|c|c|}
\hline Informants & Role in Project Implementation & Data Collection \\
\hline Operator 1 & $\begin{array}{l}\text { Is operating the production line } \\
\text { where the system is implemented }\end{array}$ & $\begin{array}{l}\text { Semi-structured interviews } \\
\text { Observation }\end{array}$ \\
\hline Operator 2 & $\begin{array}{l}\text { Is operating the production line } \\
\text { where the system is implemented }\end{array}$ & $\begin{array}{l}\text { Semi-structured interviews } \\
\text { Observation }\end{array}$ \\
\hline Department manager & $\begin{array}{l}\text { First-line manager for the } \\
\text { operators and responsible for daily } \\
\text { production performance }\end{array}$ & $\begin{array}{l}\text { Semi-structured interviews } \\
\text { Observations } \\
\text { Access to archival data }\end{array}$ \\
\hline Factory manager & Approved the project and funding & $\begin{array}{l}\text { Semi-structured interviews } \\
\text { Access to archival data }\end{array}$ \\
\hline Project Engineer 1 & $\begin{array}{l}\text { Project manager for local } \\
\text { implementation }\end{array}$ & $\begin{array}{l}\text { Semi-structured interviews } \\
\text { Access to archival data }\end{array}$ \\
\hline Project Engineer 2 & $\begin{array}{l}\text { Project manager for global } \\
\text { implementation across four } \\
\text { manufacturing sites }\end{array}$ & $\begin{array}{l}\text { Semi-structured interviews } \\
\text { Access to archival data }\end{array}$ \\
\hline Maintenance engineer & $\begin{array}{l}\text { Responsible for the overall } \\
\text { maintenance of the production } \\
\text { where the system is implemented }\end{array}$ & Semi-structured interviews \\
\hline Technology supplier & $\begin{array}{l}\text { Responsible for delivering the } \\
\text { technical solution and training }\end{array}$ & Semi-structured interviews \\
\hline
\end{tabular}

As our fieldwork progressed, and as we, in an iterative process, moved between the field, the literature, and the development of our analysis, it became apparent that we needed to expand our unit of analysis. Fully understanding the barriers to utilizing new real-time operational data called for a broader organizational view and a more in-depth study of the case company's learning environment, problem-solving capabilities, and leadership practices. We, therefore, decided to expand our sample and divide them into four groups of informants, representing the broader organizational context within the case company. In Table 3, we outline the four groups. 
Table 3. Case study sources (second sampling).

\begin{tabular}{ccc}
\hline Informants & Role & Data Collection \\
\hline Line management & $\begin{array}{c}1 \text { general manager, 2 factory managers } \\
\& \text { 4 department managers }\end{array}$ & $\begin{array}{c}\text { Semi-structured interviews } \\
\text { Observations } \\
\text { Access to archival data } \\
\text { Focus group interviews }\end{array}$ \\
\hline Internal lean resources & $\begin{array}{c}1 \text { lean manager \& 3 local lean } \\
\text { representatives }\end{array}$ & $\begin{array}{c}\text { Semi-structured interviews } \\
\text { Observations } \\
\text { Access to archival data }\end{array}$ \\
\hline Support functions & $\begin{array}{c}\text { 1 HR manager, 1 Finance director, 2 } \\
\text { controllers, 1 QHSE manager, 1 } \\
\text { Maintenance manager, 1 logistic } \\
\text { manager \&1 IT responsible }\end{array}$ & $\begin{array}{c}\text { Semi-structured interviews } \\
\text { Focus group interview } \\
\text { Access to archival data }\end{array}$ \\
\hline Operators & 8 operators (including 2 union \\
& representatives) & $\begin{array}{c}\text { Semi-structured interviews } \\
\text { Focus group interviews } \\
\text { Observation }\end{array}$ \\
\hline
\end{tabular}

We considered line management as a central group of informants since they, firstly, provided us with knowledge of the intentions and assumptions behind the decisions made about adopting lean management and new technology. Secondly, they provided us with knowledge of what strategies and approaches they, as managers, applied to develop their organization's lean management capabilities in general and to utilize new real-time OEE data. Thirdly, they were the primary means of observing existing leadership practices.

Internal lean resources provided in-depth knowledge of how the case company practices lean management. They also provided knowledge on what lean management methods and practices are currently adopted and how they train leaders and operators to apply lean to their daily work routines.

We chose the support functions to find out how the case company's production system and value chain was functioning. Furthermore, they also provided knowledge of organizational barriers and enablers for utilizing lean management in conjunction with real-time OEE data, due to their different professional backgrounds and high-level of competences within the areas of IT, HR, Logistic, QHSE, Maintenance, and Finance.

The operators provided us with knowledge of how they apply lean management methods and practices on the shop floor. They also provided us with insight to enablers and barriers to adopting the new real-time OEE data gathering systems, from their perspective. Furthermore, they could reveal potential gaps between the leaders' espoused theory and the theory-in-use regarding their lean leadership practices.

By collecting data from different sources and applying different methods of data collection, we were able to capture different non-technological dimensions of why the manufacturer was not able to utilize real-time data systems. Furthermore, the applied data triangulation also enabled us to ensure cross-validation of the data, consistency of the findings, and overall trustworthiness.

\subsubsection{Interviews}

The purpose of the applied semi-structured interviews during the first interview round was to explore how the different informants perceived and experienced the implementation, commission, and utilization of the new real-time operational data gathering system. The interview questions were therefor composed to accommodate an open and explorative approach to gaining knowledge of the phenomenon in question from a LO perspective. Based on the knowledge gained from the first interview round, a set of themes rooted in LM and LO literature emerged. We, therefore, compiled a new set of interview questions based on existing LM and LO literature to get a deeper understanding of these factors at the case company. In Table 4, we have listed the questions compiled and the underlying literature references that prompted their inclusion. 
Table 4. Interview guide.

\begin{tabular}{|c|c|c|}
\hline First Sampling Round & Second Sampling Round & Second Sampling Round References \\
\hline $\begin{array}{l}\text { What is your role regarding the implementations and } \\
\text { utilization of the new real-time OEE gathering system? } \\
\text { How do you see the purpose behind implementing the } \\
\text { new real-time OEE gathering system? } \\
\text { What activities were you involved in? } \\
\text { What did you expect from the new real-time OEE } \\
\text { gathering system before implementation? } \\
\text { What has happened after the implementation of the new } \\
\text { real-time OEE gathering system? } \\
\text { What have you learned from implementing the new } \\
\text { real-time OEE gathering system? } \\
\text { What obstacles have you experienced in using the new } \\
\text { real-time OEE gathering system to improve performance? } \\
\text { (Technical, managerial, organizational and competence) } \\
\text { What would it take to utilize the real-time OEE gathering } \\
\text { system for improving performance thoroughly? }\end{array}$ & $\begin{array}{c}\text { How is lean management practiced at the factory? } \\
\text { How is performance improved at the factory? } \\
\text { What do you see as the biggest obstacle in } \\
\text { improving performance? } \\
\text { How are operational problems being solved at } \\
\text { the factory? } \\
\text { How is learning practiced at the factory? } \\
\text { How do you leverage digital technologies to } \\
\text { improve performance? } \\
\text { What do you see as the biggest obstacles for } \\
\text { implementing and leveraging digital } \\
\text { technologies to improve performance? } \\
\text { How are operators developed to improve } \\
\text { performance? } \\
\text { How are operators developed to utilize new } \\
\text { technology to improve performance? } \\
\text { How do you develop, execute, and follow up on } \\
\text { your digital strategy? }\end{array}$ & {$[14,17,19,20,29,31,33,36,38,51]$} \\
\hline
\end{tabular}

We conducted all interviews as free-flowing dialogues. During the interviews, the investigator made sure that the questions in the interview guide were covered; however, they were not necessarily covered in a particular order. The informants were also encouraged to discuss their approach to LM and problem solving in general. The semi-structured interviews lasted $45 \mathrm{~min}$ each, and we digitally recorded them together with reflective notes. With two operators, we conducted an additional follow-up interview.

\subsubsection{Focus Group Interviews}

To acquire more in-depth knowledge from the operators' perspective on how the case company applies lean management to solve operational problems and utilize new technology to improve performance, we conducted two focus group sessions [52,53]. A focus group interview was applied to get direct access to how operators at the case company talk and think about applying LM, problem solving, and how technology can enable process improvements. As opposed to a semi-structured interview, we were able to get a more authentic and natural response from the informants. The dialogue among the informants provides observable data to analyze, which would be less accessible without interaction and discussion between them [53].

For each of the two focus group interviews, four operators were selected based on diversity in tenure, gender, production unit, and attitude towards lean management and problem solving. The duration of the focus group interviews was $60 \mathrm{~min}$. We prompted the groups with three questions: (1) How does it feel working at the case manufacturer? (2) How do you utilize lean management to improve production performance? (3) How do you utilize new technology to improve production performance? To ensure that some informants did not dominate the discussions while others faded into the background, we asked them to pick one or two pictures that illustrated their view on the question prompted by us. The informants could choose between 100 different pictures. The informants told their stories behind the chosen pictures, capturing a more nuanced understanding of their underlying assumptions behind their responses to the questions asked. Furthermore, it also elevated the dialogue among the informants as shared stories behind the pictures started to unfold.

We also conducted another form of a group interview with the line management and selected managers from the support functions. At this group interview, we presented the initial findings from the conducted analysis and subsequently engaged in discussing the content. We did this to obtain the advice and perspective of key stakeholders to understand the phenomenon studied [54]. In practice, we prompted the informants with posters showing the initial findings and conclusions from the conducted analysis. We then asked them to note down their comments on post-its. Subsequently, we facilitated a group discussion around each of the posters. The group interview had a duration of two hours. We digitally recorded all the group interviews in combination with reflective notes. 


\subsubsection{Observations}

To acquire more in-depth knowledge of the theories in use regarding problem solving and the leaders' supportive learning behaviors, we conducted several hours of both direct and participative observations in addition to the data collected from the interviews [49]. For six months, the first author conducted observations of daily operational status meetings, problem solving and prioritization meetings, two four-day process improvement workshops, team meetings, and management meetings. Throughout the study, the first author documented observations in field notes and research diaries.

\subsubsection{Archival Data}

Complimenting the study, the following archival data were collected: operational performance and operational data, project briefs and plans, internal LM guides, and internal company articles about the application of LM and new digital technology. Besides providing us with useful background information, we used these secondary data to validate our initial findings and conclusion.

\subsection{Analysis and Coding}

Collecting data from diverse sources and applying various methods of data collection enabled us to capture non-technological variables as to why the manufacturer was unable to utilize real-time data. Furthermore, the applied data triangulation also enabled us to ensure cross-validation of the data, consistency of the findings, and overall trustworthiness [54].

To code and analyze the collected data, we applied Braun and Clarke's [55] (p.87) six-steps thematic analysis in combination with Saldaña's [56] guide to coding, as depicted in Table 5. In operations management research, both approaches are commonly used, e.g., [48,57].

Table 5. Phases of the applied thematic analysis method (reprinted [55] (p.3)).

\begin{tabular}{ccc}
\hline Phase & Description of Process \\
\hline 1. Familiarizing yourself with your data: & $\begin{array}{c}\text { Transcribing data (if necessary), reading, and re-reading the } \\
\text { data, noting down initial ideas. }\end{array}$ \\
\hline 2. Generating initial codes: & $\begin{array}{c}\text { Coding interesting features of the data in a systematic fashion } \\
\text { across the entire data set, collating data relevant to each code. }\end{array}$ \\
3. Searching for themes: & $\begin{array}{c}\text { Collating codes into potential themes, gathering all data } \\
\text { relevant to each potential theme. }\end{array}$ \\
4. Reviewing themes: & $\begin{array}{c}\text { Checking if the themes work in relation to the coded extracts } \\
\text { (Level 1) and the entire data set (Level 2), generating a } \\
\text { thematic 'map' of the analysis. }\end{array}$ \\
\hline 5. Defining and naming themes: & $\begin{array}{c}\text { Ongoing analysis to refine the specifics of each theme and the } \\
\text { overall story the analysis tells, generating clear definitions } \\
\text { and names for each theme }\end{array}$ \\
\hline 6roducing the report: & $\begin{array}{c}\text { The final opportunity for analysis. Selection of vivid, } \\
\text { compelling extract examples, final analysis of selected } \\
\text { extracts, relating back of the analysis to the research question } \\
\text { and literature, producing a scholarly report of the analysis. }\end{array}$ \\
\hline
\end{tabular}

\section{Results}

\subsection{The Utilization of Real-Time Operational Data Requires Operator-Initiated Problem Solving}

Before implementing the real-time operational data gathering system, OEE data was registered manually on paper by the operators. These data were then collected by the local lean responsible weekly and reported to management. According to the local lean responsible, it was rare that the data were analyzed and used: "I print all the numbers every Monday, but nothing happens, and we have no time to go down and analyze the numbers".

There also seemed to be a widespread basic underlying assumption among the operators that their role is not to engage actively in problem solving but 'only' to generate ideas for problem 
solving or improvements, then let maintenance handle them. During a focus group interview with the operators, one expressed this basic underlying assumption, saying: "It is easy to generate ideas, but there is nobody to execute them."

The same behavior and basic underlying assumption were also apparent in terms of machine maintenance. They used manually gathered OEE data to prioritize which production lines and machines the maintenance department should focus on fixing at a bi-weekly meeting. However, despite management ambition to conduct preventive maintenance, repairs were mainly carried out when equipment caused unplanned downtime. One of the operators explained this reactive approach to maintenance like this: "We do not work much with preventive maintenance. We do not have the time, and we just call the maintenance department when the machines break down".

It was the presence of this reactive, firefighting behavior to problem solving and maintenance that the leaders in the case company were seeking to change with the implementation of the real-time operational data gathering system. However, six months after its implementation, the case company could ascertain no significant change in behavior or improvement in performance. The operators confirmed the lack of changed behavior during a focus group interview: "We do not use the data from the real-time data gathering system since it is not our system, it is maintenance's, so they can see what they need to fix." Another indicator supporting the fact that the operators had not altered their daily work practice to utilize the real-time operational data was when the operational gathering system had been out of order for over a week. The operators knew that the system had stopped working but did not escalate the problem. It was a project engineer who discovered and corrected it.

Despite the presence of operational data in real-time, the procedure for utilizing the operational data was the same as before implementation. The local lean responsible still gathered the OEE data weekly to submit a report to the management. They also still conducted prioritization meetings between the production department leader, the local lean responsible, and the maintenance department on a bi-weekly basis.

\subsection{First-Order Problem Solving PrevalentAapproach to Reducing Unplanned Machine Downtime}

Before implementing the real-time operational gathering system, applying second-order problem solving was not a widespread capability among operators. Problem solving based on PDCA was only conducted occasionally in cases of critical quality issues. In these cases, the quality department performed the problem solving.

As illustrated in Figure 2, the prevalent problem-solving behavior observed among operators and maintenance specialists can be characterized as overcoming the immediate obstacle, assuming what the problem is, short term-fixes, and ignoring the underlying root cause. If the short-term fixes do not result in resuming regular operation, then the maintenance department will be contacted to re-start the machine. This observation was supported by a leader who explained: "We are often saying that we really need to get to the bottom of this and identify the root causes, but we do not."

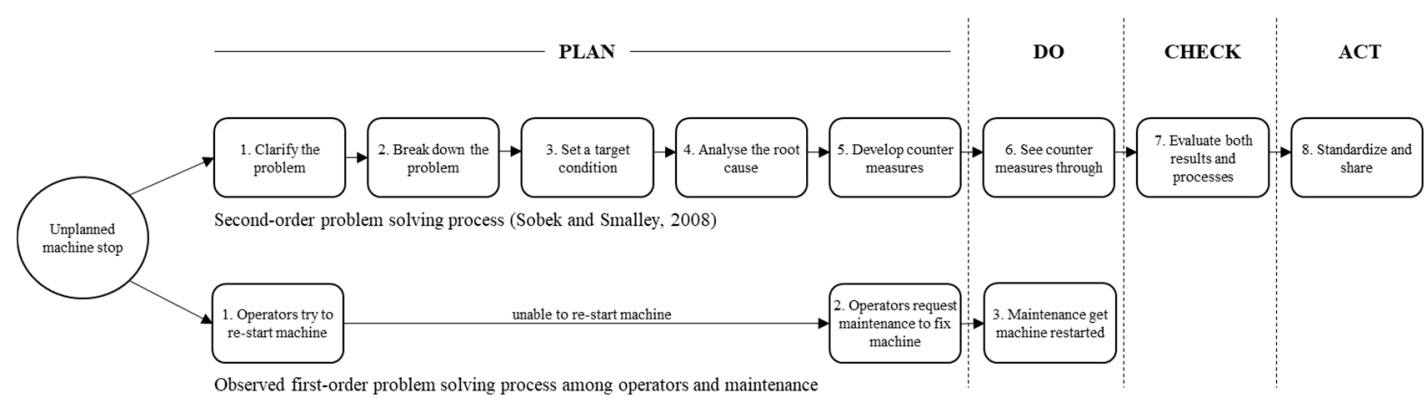

Figure 2. The operators' and maintenance specialists' prevalent problem-solving approach (source: first authors' observation). 
It is important that operators begin to start acting on real-time operational data, but more important still is that they do this by applying daily second-order problem-solving based on PDCA, as depicted in Figure 2. The operators were familiar with several of the LM problem-solving tools and methods introduced by the global lean department. However, our observations revealed that the operators only performed first-order problem solving [36]. Due to the underlying basic assumption among operators that it is not their responsibility to identify the root causes preventing machines from running could explain why first-order problem solving is the prevalent practice when handling unplanned machine stops. "We are only doing firefighting," as one of the operators explained.

As Tucker et al. [36] observed among nurses, there also seemed to be a prevalent heroic attitude among the maintenance specialists. When machines break down, they often come and "save the day" by fixing the machine. This behavior fuels a psychological gratification, which maintains the observed first-order problem-solving behaviors. "We honor the firefighters," one of the leaders reasoned in an interview.

Shortly after implementing the real-time operational data system, the maintenance department initiated a set of 11 specific fixes. From observing the implementation of these 11 fixes, we identified two clear examples of first-order problem solving. Firstly, the 11 fixes were initiated at the same time without any specification of what gap or deviation in performance they intended to close. The maintenance department was, therefore, not able to evaluate if the fixes had worked and, eventually, which of the fixes worked the best. Investigating the effects of the fixes revealed that they had not improved performance significantly. Secondly, according to the operators, the fixes were not initiated based on OEE data. The operators explained that the initiated fixes had been on their wish list for a long time, and now management had approved them due to renewed attention on their production lines' performance as a result of the real-time operational data gathering system implementation.

\subsection{Real-Time Data System Perceived as Coercive}

Our findings identified that the new real-time operational data gathering system implementation was carried out by experts and specialists from the support functions. Despite their intention, the specialists had not involved the operators in identifying the best real-time operational data gathering system and how to implement it. Before implementation, the operators only participated in an introduction to the system delivered by the technology supplier. After the implementation, the operators only received training in the technical use of the system. Once the functionality of the system was up and running, the experts and specialists from the support functions were off to the next project, and the employees were left alone to ensure utilization of the new real-time operational data gathering system to improve performance.

This coercive formalization approach to implementing the new real-time operational data gathering system adopted by the support functions specialist had several consequences contributing to unsuccessful implementation [29]. Firstly, it maintained the operators in the existing first-order problem-solving approach, as depicted in Figure 2, where they were not cooperating with others in conducting the analysis and making decisions on how to improve or fix the machines they were operating: "After the implementation, I still gather data once a week and type it in, and the only change is that I now can get them from the system instead". Secondly, it strengthened the underlying assumption that it is only the support functions experts and specialists who can identify and implement new technology. "Only ideas of implementing new technology from the engineers get implemented", one of the operators responded. Thirdly, the operators ended up perceiving that the new real-time operational data gathering system was imposing constraints on their work by adding new tasks in terms of interacting with the system. This perception was clouding the intention for the system to enable operators to reveal opportunities for improvement and problem-solving.

Despite the opposite intention behind implementing the real-time operational data gathering system, the operators did not perceive that the feedback received from the system was useful to them in their efforts to improve production performance. Instead, they believed that the 
new real-time operational data gathering system was only put in place to help management and maintenance get a better understanding of the production lines' performance: "We do not need the new system to tell us what is wrong with the machines."

For the operators to utilize the new real-time data gathering system to improve performance, it is also vital to ensure a practice of problem-solving and continuous improvement across departmental siloes. However, the expected outcome of the implementation of the system also failed to appear in this regard. "I expected closer integration between maintenance and production after the system implementation, but it did not happen," the maintenance supervisor explained. One of the operators supported the leader: "We still do not work much together across the factory. If we all helped each other, things would be better".

\subsection{Poor Learning Environment and Learning Processes}

At first glance, one would expect the existence of a supportive learning environment at the place of manufacture, since operators articulate the presence of psychological safety [58]. Operators feel they can speak up about what is on their mind. We observed several meetings supporting the notation that employees can speak freely. At one meeting, an operator complained about the planning department to his leader while the head of planning was present in the room. Our findings did furthermore not indicate a culture where the operators are reprimanded for failures and therefore try to hide them.

However, a supportive learning environment consists of more than psychological safety. A central element is allocating time to experiment and reflect on how to improve work routines in conjunction with new technology [31,59]. Our data analysis revealed that operators felt that there was no time allocated to engage in improving work routines: "We do not have time to make improvements; after 11 hours on the job, I just want to go home". The operators explained the lack of time available to develop new work routines as a result of high workload. "We start up a lot but do not finish much. We want to do everything at the same time," one of the leaders responded.

Another critical element of a supportive learning environment and learning processes is conducting experiments in a structured way [43]. Despite management's willingness to experiment with new technologies, the execution of experiments could also be characterized as first-order problem-solving. A contributing factor was difficulties in defining a concrete deviation or gap from the desired state, e.g., it was observed that a perceived solution was often defined as the goal itself instead of a means to achieving a specific performance improvement goal. When this was the case, it was difficult to subsequently follow-up and reflect on the learning from an experiment and evaluate the effects [43].

\subsection{Leaders Not Demonstrating Support for Learning}

Based on the interviews and observations, a gap between leaders' espoused theory and theory-in-use emerged [60]. The leaders had the following perception of their leadership behavior. One stated: "leadership is for me to listen to the employees and identify what needs to be done for them to do their best and be a success". "Another leader explained", "My job is to help and coach the employees to improve performance and reach our strategic goals". Furthermore, a third leader replied, "As a leader, I must be visible and give the employees feedback". This perception is in sharp contrast to how the operators experience their leaders. "I feel that the leaders do not listen to us. I would like them to exhibit more interest in our work", as one operator explained. Another operator felt that: "It is often difficult to get hold of my leader. They only come when the KPIs (Key performance indicators) are in red, and then they expect us to fix it".

Perceptions of the leader's current presence and support held the operators also indicate a behavioral gap related to the principle of 'going to Gemba'. According to the operators, the leaders are rarely observed going to the shop floor to understand the current situation and mentoring or coaching the operators in solving problems or conducting improvements [20].

Even though the leaders' espoused theories of commitment to developing their employees, they instead exhibited a prevalent behavioral script of first-order problem solving. As operators, 
they handle their leadership and operational problems with short term fixes [41]. It was, for example, observed that the leaders handle imminent production challenges by shuffling operators around as opposed to proactively enabling and empowering them to initiate second-order problem solving and address the underlying root causes within the operational system. An observed and explaining factor behind this predominant behavior is the primary focus on short-term and urgent matters. As one of the leaders reflected: "We always feel that we are behind. I would like to get in front of things and be proactive instead of just firefighting".

Another observed behavioral script among the leaders, which prevents the operators from engaging in second-order problem solving, is the preference of setting the destination as a fixed goal or the implementation of a solution as opposed to a direction. This behavior reflects habits of giving the answers to what the operators should do to fix a problem instead of asking questions that fuel reflection, learning, and development among operators. It was, for example, observed in an operation status meeting that the highest-ranking leader only asked six open-ended questions but came with 64 orders and evaluating remarks during the meeting.

\section{Discussion}

The identified themes constitute the groundwork for the conceptual model depicted in Figure 3. Based on empirical findings and observations from studying the case company's implementation, commissioning, and utilization of their new real-time gathering system, we propose the conceptual model illustrated in Figure 3. The study implies, from a LO perspective, that for operators to utilize real-time operational data and harvest the benefits of significantly reducing the time spent identifying and correcting operational issues like unplanned machine stops in order to prevent operational issues from happening, manufactures need to overcome a set of related barriers.

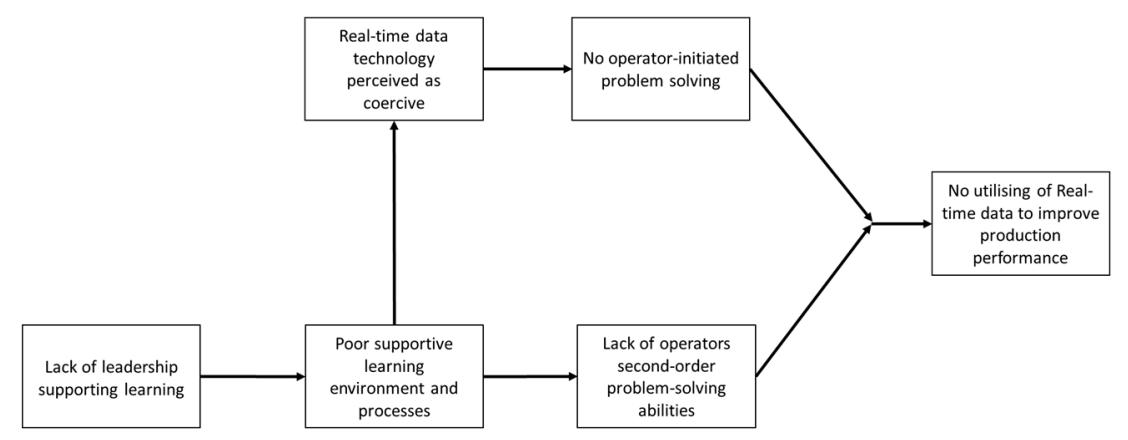

Figure 3. Barriers to utilizing real-time operational data in a manufacturing context, from a LO perspective.

\subsection{No Utilizing of Real-Time Data to Improve Production Performance if Operators Do Not Initiate Problem Solving}

Our empirical findings indicate that, despite knowledge of LM tools and methods to perform problem solving and training with the real-time operational data gathering system, the operators did not adopt new routines and work practices to improve performance proactively. Our findings indicate that if manufacturers intend to move towards proactive operator-initiated problem solving, the technical implementation of real-time operational data gathering technology is not enough. Applying a solely technical focus on implementing new technology will not in itself enable operators to initiate problem solving and utilize real-time operational data. Manufactures must firstly, together with the operators, institute new routines and work procedures; thus, it is the operator's responsibility to initiate problem solving daily when deviations from planned operations occur. Otherwise, the benefits of having real-time data available are not achievable. 


\subsection{Lack of Second-Order Problem-Solving Abilities Among Operators Prevents Them from Utilizing Real-Time Data}

Our findings support the notion that the lack of second-order problem solving abilities among operators, including a structured approach to learning, experimentation, and reflections, is one of the explaining factors preventing the utilization of real-time operational data. Only practicing first-order problem solving prevents the organization from engaging in the deeper thinking required to practice second-order problem solving. It also prevents them from adjusting their day-to-day work routines so that, once formalized in an enabling way, they can utilize real-time operational data [29,42]. I4.0 technologies cannot replace human cognitive processed related to the operators' reflection and imagination when identifying root causes behind production problems and countermeasures for resolutions and improvements [1]. We can, therefore, also conclude that operator-initiated problem solving entails both developing and empowering the operators to perform daily second-order problem solving [36].

\subsection{A Coercive Perception of Real-Time Data Systems Among Operators Prevents Them from Initiating Problem Solving Based on Real-Time Data}

An explaining factor of why the operators did not utilize the new real-time operational data system was that they perceived it as coercive and a system serving management and support functions as opposed to enabling them to, e.g., more effectively handle unplanned production stops and eventually prevent them [29]. Despite the opposite intention of implementing the real-time operational data gathering system, the operators do not perceive that the feedback received from the system is useful for them in their efforts to improve production performance [46]. Instead, they feel that they must perform additional non-value-adding work procedures to accommodate management and the maintenance department in getting a better understanding of the production lines' performance.

\subsection{Poor Supportive Learning Environments and Learning Processes Disseminate a Coercive Formalization of Real-time Operational Data Utilization and Hinder Developing Operators' Second-Order Problem-Solving Capabilities}

Despite a high level of psychological safety, the operators are not sufficiently engaged and empowered to find out how to utilize real-time operational data. If the current learning environment was supportive, the operators would be involved as active participants during the implementation and commissioning of the real-time operational data system. Management and specialists would have facilitated the operators in finding the best practices when it came to using the new system and integrating it into their daily practices $[29,31]$.

Our findings reveal that the presence of a poor supportive learning environment and learning processes upholds first-order problem-solving behaviors of quickly fixing problems in the case of unplanned stops. The current learning environment is preventing the operators from being proactive in eliminating unplanned stops instead of expecting the maintenance department and management to act. An explaining factor is that there is no allocated time or structured approach to learning, experimentation, and reflection, in addition to deviations not being embraced as learning opportunities by leaders and operators.

Furthermore, training in the new system was not contextual. Marsick and Watkins [32] confirm the importance of contextual training. They point out that it is essential that learning is an integrated part of the operator's daily work, which includes the ability to solve problems together with co-workers. Developing and empowering the operators to perform daily second-order problem solving must, therefore, be facilitated by the presence of a supportive learning environment and processes [31,32]. 


\subsection{Lack of Leadership Supporting Learning Disseminates Poor Supportive Learning Environments and Processes}

The leaders' behaviors are essential in establishing a supportive learning environment and learning processes, where, for example, the operators are enabled to utilize real-time operational data to improve production performance [19,31]. Our empirical findings indicate a gap between the leaders' espoused theories of how they aspire to enable, develop, and empower the operators and the theory-in-use $[17,39]$. The gaps identified from the empirical findings and observations were, e.g., related to the leaders' inadequate practice of being present, 'going to Gemba', asking questions instead of telling, and coaching and mentoring practices towards the operators. Similarly, as the operators must solve specific operational problems by conducting second-order problem solving, the leaders also must perform second-order problem solving. The difference is that the leaders focus on a higher-level problem of how to develop a supportive learning environment and learning processes instead. We observed no sign of committing to the daily development of operators during their problem-solving and improvement activities [19].

\subsection{Initial Example from Explicitly Addressing the Identified Barriers}

After being presented with the findings from the analysis, the manufacture decided to engage with the first author in an action-learning experiment that addresses the identified barriers. The action-learning experiment consists of two action-learning interventions. In the first action-learning intervention, two department managers, together with their factory manager, were selected to undergo intensive training in second-order problem solving [38] and problem-solving coaching [44]. During this action-learning intervention, the managers solved a concrete problem by coaching each other, supervised by the first author. Subsequently, in the second action-learning intervention, each department manager selected two groups of operators to work on a concrete operational problem concerning production lines where real-time data were available. For four weeks, the department manager would coach and support the operators in solving the selected problems. Simultaneously, the factory manager would coach the department managers on their effort to support the operators. Based on initial anecdotes, operational data and observations, one department improved performance by $10 \%$ on one of their production lines during the second action-learning intervention by conducting second-order problem solving and utilizing the new real-time operational data systems.

\section{Conclusions}

Our scientific contribution is firstly to identify specific non-technological barriers that prevent manufactures from enabling their organization to explore and exploit real-time operational data from a LO perspective. We attain this by proposing a conceptual model (Figure 3) based on the theoretical notions of second-order problem solving [36], enabling formalization [29], fostering a supportive learning environment, and processes [31,32] and leadership that supports learning [19,31]. The cross-fertilizing of these theoretical notions within the conceptual model helps us to understand what it requires to implement new learning routines and work practices on the manufacturing shop floor and utilize real-time operational data proactively. Secondly, our finding suggests that effective implementation and commissioning of Industry 4.0 technologies, like real-time operational data, requires the existence of an LM environment. However, this does not only mean a technocentric LM environment where organizational members have been introduced and trained in LM tools and methods, but an LM environment conjoined with a supportive learning environment and supportive leadership. Thirdly, the study adds to recent survey-based research by getting behind statistical numbers and understanding how LM and I4.0 are empirically associated through the non-technical lens of LO in a manufacturing context.

The practical implications derived from this study suggest that manufacturers cannot rely on a solely technological focus when implementing I4.0 technologies and linking them with existing or new LM capabilities. For manufactures to ensure a successful return of investment from acquiring new I4.0 
technologies, they need to balance both technical and non-technical perspectives. New technology does not automatically bring about desired changes to operators' behaviors that result in them utilizing these technologies just by implementing them. Despite the best designs and intentions, manufactures must also consider how to advance their second-order problem-solving abilities. The study, therefore, advises manufacturers to develop their leaders' ability to grow a supportive learning environment and implement learning practices, ensuring that, as new data generating I4.0 technology gets implemented, underlying work routines and practices are formalized in an enabling way.

A limitation of this in-depth single case study is its generalizability. This single case study is limited to the specific context of the utilization of real-time operational data in a manufacturing setting in Denmark and, therefore, is not able to extrapolate any statistical generalization for other contexts [50]. The analytical generalizability of the study is based on solid theories of why manufacturers are not able to utilize real-time data and how to link LM and I4.0 from the non-technical perspective of LO. Therefore, further research should validate the conceptual model from this study statistically across different manufacturing organizations for different markets and locations. Additionally, future research should examine how manufacturers can overcome the identified barriers, e.g., examine the effect that developing leaders' ability to grow a supportive learning environment and the effect that learning processes have on formalizing underlying work routines in an enabling way when utilizing new I4.0 technologies in an LM environment.

Author Contributions: Conceptualization, H.S.; methodology, H.S.; validation, H.S., T.B.K. and B.V.W.; formal analysis, H.S.; investigation, H.S.; resources, H.S.; data curation, H.S.; writing-original draft preparation, H.S.; writing-review and editing, H.S.; visualization, H.S.; supervision, T.B.K. and B.V.W.; project administration, H.S.; All authors have read and agreed to the published version of the manuscript.

Funding: Innovation Fund Denmark funded this research, grant number 9065-00123B.

Conflicts of Interest: The authors declare no conflict of interest.

\section{References}

1. Rosin, F.; Forget, P.; Lamouri, S.; Pellerin, R. Impacts of industry 4.0 technologies on lean principles. Int. J. Prod. Res. 2020, 58, 1644-1661. [CrossRef]

2. Tortorella, G.L.; Fettermann, D. Implementation of industry 4.0 and lean production in Brazilian manufacturing companies. Int. J. Prod. Res. 2018, 56, 2975-2987. [CrossRef]

3. Pagliosa, M.; Tortorella, G.; Ferreira, J.C.E. Industry 4.0 and lean manufacturing: A systematic literature review and future research directions. J. Manuf. Technol. Manag. 2019. ahead of print. [CrossRef]

4. $\mathrm{Xu}, \mathrm{Y}$; Chen, M. Improving just-in-time manufacturing operations by using internet of things based solutions. Procedia CIRP 2016, 56, 326-331. [CrossRef]

5. Weyer, S.; Schmitt, M.; Ohmer, M.; Gorecky, D. Towards industry 4.0-Standardization as the crucial challenge for highly modular, multi-vendor production systems. IFAC-PapersOnLine 2015, 48, 579-584. [CrossRef]

6. Israelsen, P. Variability-Based Management Accounting; Jurist- Og Økonomforbundets Forlag: Copenhagen, Denmark, 1993.

7. Buer, S.-V.; Strandhagen, J.O.; Chan, F.T.S. The link between industry 4.0 and lean manufacturing: Mapping current research and establishing a research agenda. Int. J. Prod. Res. 2018, 56, 2924-2940. [CrossRef]

8. Chiarini, A.; Kumar, M. Lean six Sigma and industry 4.0 integration for operational excellence: Evidence from Italian manufacturing companies. Prod. Plan. Control 2020, 1-18. [CrossRef]

9. Martinez, F. Process excellence the key for digitalisation. BPMJ 2019, 25, 1716-1733. [CrossRef]

10. Sommer, L. Industrial revolution-Industry 4.0: Are German manufacturing SMEs the first victims of this revolution? JIEM 2015, 8, 1512-1532. [CrossRef]

11. Hines, P.; Taylor, D.; Walsh, A. The lean journey: Have we got it wrong? Total Qual. Manag. Bus. Excell. 2018, 31, 389-406. [CrossRef]

12. Bortolotti, T.; Boscari, S.; Danese, P. Successful lean implementation: Organizational culture and soft lean practices. Int. J. Prod. Econ. 2015, 160, 182-201. [CrossRef] 
13. Tortorella, G.L.; Cawley Vergara, A.M.; Garza-Reyes, J.A.; Sawhney, R. Organizational learning paths based upon industry 4.0 adoption: An empirical study with Brazilian manufacturers. Int. J. Prod. Econ. 2020, 219, 284-294. [CrossRef]

14. Cho, Y.S.; Linderman, K. Metacognition-based process improvement practices. Int. J. Prod. Econ. 2019, 211, 132-144. [CrossRef]

15. Tortorella, G.L.; Fogliatto, F.S. Method for assessing human resources management practices and organisational learning factors in a company under lean manufacturing implementation. Int. J. Prod. Res. 2014, 52, 4623-4645. [CrossRef]

16. Moeuf, A.; Pellerin, R.; Lamouri, S.; Tamayo-Giraldo, S.; Barbaray, R. The industrial management of SMEs in the era of industry 4.0. Int. J. Prod. Res. 2018, 56, 1118-1136. [CrossRef]

17. Beer, M. Why total quality management programs do not persist: The role of management quality and implications for leading a TQM transformation. Decis. Sci. 2003, 34, 623-642. [CrossRef]

18. Hines, P.; Holweg, M.; Rich, N. Learning to evolve: A review of contemporary lean thinking. Int. J. Oper. Prod. Manag. 2004, 24, 994-1011. [CrossRef]

19. Liker, J.K.; Convis, G.L. The Toyota Way to Lean Leadership: Achieving and Sustaining Excellence through Leadership Development; McGraw-Hill: New York, NY, USA, 2012.

20. Dombrowski, U.; Mielke, T. Lean leadership-Fundamental principles and their application. Procedia CIRP 2013, 7, 569-574. [CrossRef]

21. Liker, J.K. The Toyota Way: 14 Management Principles from the World's Greatest Manufacturer; McGraw-Hill: New York, NY, USA, 2004.

22. Edmonson, A.; Moingeon, B. From organizational learning to the learning organization. In Essential Readings in Management Learning; Grey, C., Antonacopoulou, E.P., Eds.; Sage: London, UK; Thousand Oaks, CA, USA, 2004; pp. 21-36.

23. Ballé, M.; Chaize, J.; Jones, D. Lean as a learning system: What do organizations need to do to get the transformational benefits from Toyota's method? Dev. Learn. Org. 2019, 33, 1-4. [CrossRef]

24. Ballé, M.; Régnier, A. Lean as a learning system in a hospital ward. Leadersh. Health Serv. 2007, 20, 33-41. [CrossRef]

25. Ståhl, A.-C.-F.; Gustavsson, M.; Karlsson, N.; Johansson, G.; Ekberg, K. Lean production tools and decision latitude enable conditions for innovative learning in organizations: A multilevel analysis. Appl. Ergon. 2015, 47, 285-291. [CrossRef]

26. Staats, B.R.; Brunner, D.J.; Upton, D.M. Lean principles, learning, and knowledge work: Evidence from a software services provider. J. Oper. Manag. 2011, 29, 376-390. [CrossRef]

27. Hu, Q.; Found, P.; Williams, S.; Mason, R. Lean thinking and organisational learning: How can they facilitate each other? In Understanding the Lean Enterprise; Measuring Operations Performance; Chiarini, A., Found, P., Rich, N., Eds.; Springer International Publishing: Cham, Switzerland, 2016; pp. 61-77. [CrossRef]

28. Shahin, M.; Chen, F.F.; Bouzary, H.; Krishnaiyer, K. Integration of lean practices and industry 4.0 technologies: Smart manufacturing for next-generation enterprises. Int. J. Adv. Manuf. Technol. 2020, 107, 2927-2936. [CrossRef]

29. Adler, P.S.; Borys, B. Two types of bureaucracy: Enabling and coercive. Adm. Sci. Q. 1996, 41, 61. [CrossRef]

30. Culot, G.; Nassimbeni, G.; Orzes, G.; Sartor, M. Behind the definition of industry 4.0: Analysis and open questions. Int. J. Prod. Econ. 2020, 226, 107617. [CrossRef]

31. Garvin, D.A.; Edmonson, A.C.; Gino, F. Is yours a learning organization? Harv. Bus. Rev. 2008, 83, 109.

32. Marsick, V.J.; Watkins, K.E. Demonstrating the value of an organization's learning culture: The dimensions of the learning organization questionnaire. Adv. Dev. Hum. Resour. 2003, 5, 132-151. [CrossRef]

33. Shah, R.; Ward, P.T. Defining and developing measures of lean production. J. Oper. Manag. 2007, 25, 785-805. [CrossRef]

34. Soriano-Meier, H.; Forrester, P.L. A model for evaluating the degree of leanness of manufacturing firms. Integr. Manuf. Syst. 2002, 13, 104-109. [CrossRef]

35. Spear, S.; Bowen, K.H. Decoding the DNA of the Toyota production system. Harv. Bus. Rev. 1999, 77, 97-106.

36. Tucker, A.L.; Edmondson, A.C.; Spear, S. When problem solving prevents organizational learning. J. Org. Chang. Manag. 2002, 15, 122-137. [CrossRef]

37. Deming, W.E. Out of the Crisis; Massachusetts Institute of Technology, Center for Advanced Engineering Study: Cambridge, MA, USA, 1986. 
38. Shook, J. Managing to Learn: Using the A3 Management Process. to Solve Problems, Gain Agreement, Mentor and Lead; Version 1.0.; Lean Enterprise Institute: Cambridge, MA, USA, 2008.

39. Emiliani, M.L. Linking leaders' beliefs to their behaviors and competencies. Manag. Decis. 2003, 41, 893-910. [CrossRef]

40. Pearce, A.; Pons, D. Implementing lean practices: Managing the transformation risks. J. Ind. Eng. 2013, 2013, 1-19. [CrossRef]

41. Choo, A.S.; Nag, R.; Xia, Y. The role of executive problem solving in knowledge accumulation and manufacturing improvements. J. Oper. Manag. 2015, 36, 63-74. [CrossRef]

42. Browning, T.R.; Heath, R.D. Reconceptualizing the effects of lean on production costs with evidence from the F-22 program. J. Oper. Manag. 2009, 27, 23-44. [CrossRef]

43. Repenning, N.P.; Sterman, J.D. Capability traps and self-confirming attribution errors in the dynamics of process improvement. Adm. Sci. Q. 2002, 47, 265. [CrossRef]

44. Rother, M. Toyota Kata: Managing People for Improvement, Adaptiveness and Superior Results; McGraw-Hill Professional Publishing: New York, NY, USA, 2009.

45. MacDuffie, J.P. The road to "root cause": Shop-floor problem-solving at three auto assembly plants. Manag. Sci. 1997, 43, 479-502. [CrossRef]

46. De Treville, S.; Antonakis, J. Could lean production job design be intrinsically motivating? Contextual, configurational, and levels-of-analysis issues. J. Oper. Manag. 2006, 24, 99-123. [CrossRef]

47. Kristensen, T.B. Enabling use of standard variable costing in lean production. Prod. Plan. Control 2020, 1-16. [CrossRef]

48. Ketokivi, M.; Choi, T. Renaissance of case research as a scientific method. J. Oper. Manag. 2014, 32, 232-240. [CrossRef]

49. Voss, C.; Tsikriktsis, N.; Frohlich, M. Case research in operations management. Int. J. Oper. Prod. Manag. 2002, 22, 195-219. [CrossRef]

50. Yin, R.K. Case Study Research and Applications: Design and Methods, 6th ed.; SAGE: Los Angeles, CA, USA, 2018.

51. Anand, G.; Ward, P.T.; Tatikonda, M.V.; Schilling, D.A. Dynamic capabilities through continuous improvement infrastructure. J. Oper. Manag. 2009, 27, 444-461. [CrossRef]

52. Giordani da Silveira, W.; Pinheiro de Lima, E.; Deschamps, F.; Gouvea da Costa, S.E. Identification of Guidelines for Hoshin Kanri Initiatives. Int. J. Product. Perf Manag. 2018, 67, 85-110. [CrossRef]

53. Ryan, K.E.; Gandha, T.; Culbertson, M.J.; Carlson, C. Focus group evidence: Implications for design and analysis. Am. J. Eval. 2014, 35, 328-345. [CrossRef]

54. Van de Ven, A.H. Engaged Scholarship: A Guide for Organizational and Social Research; Oxford University Press: Oxford, UK; New York, NY, USA, 2007.

55. Patton, M.Q. Qualitative Research E Evaluation Methods: Integrating Theory and Practice, 4th ed.; SAGE Publications, Inc.: Thousand Oaks, CA, USA, 2015.

56. Braun, V.; Clarke, V. Using thematic analysis in psychology. Qual. Res. Psychol. 2006, 3, 77-101. [CrossRef]

57. Saldaña, J. The Coding Manual for Qualitative Researchers, 2nd ed.; SAGE: Los Angeles, CA, USA, 2013.

58. Leite, H.; Bateman, N.; Radnor, Z. Beyond the ostensible: An exploration of barriers to lean implementation and sustainability in healthcare. Prod. Plan. Control 2020, 31, 1-18. [CrossRef]

59. Edmondson, A. Psychological safety and learning behavior in work teams. Adm. Sci. Q. 1999, 44, 350. [CrossRef]

60. Wiersma, E. Conditions that shape the learning curve: Factors that increase the ability and opportunity to learn. Manag. Sci. 2007, 53, 1903-1915. [CrossRef]

Publisher's Note: MDPI stays neutral with regard to jurisdictional claims in published maps and institutional affiliations.

(C) 2020 by the authors. Licensee MDPI, Basel, Switzerland. This article is an open access article distributed under the terms and conditions of the Creative Commons Attribution (CC BY) license (http://creativecommons.org/licenses/by/4.0/). 